\title{
O ENSINO DE HARDWARE DE COMPUTADORES UTILIZANDO COMO ALTERNATIVA DIDÁTICA A ROBÓTICA EDUCACIONAL E A APRENDIZAGEM BASEADA EM PROJETOS
}

\section{Computer Hardware Teaching Using Educational Robotics and Project-Based}

Learning as a Didactic Alternative

\author{
Marcos Juares Vissoto Corino* \\ Silvia de Castro Bertagnolli ** \\ Marcelo Augusto Rauh Schmitt ${ }^{* * *}$
}

\begin{abstract}
Resumo: Este trabalho descreve uma abordagem pedagógica para o ensino de hardware de computadores por meio da robótica educacional. Para isso, foram utilizadas a aprendizagem baseada em projetos e a robótica educacional, sustentadas pela aprendizagem significativa com o propósito de tornar a aprendizagem mais dinâmica e contextualizada aos desafios que o futuro técnico em informática terá ao exercer sua profissão. A pesquisa-ação mostrou que a aprendizagem de hardware pode ser favorecida com essa abordagem, além de possibilitar o engajamento dos alunos nas aulas, promovendo o desenvolvimento de competências técnicas, sociais e emocionais nos estudantes.
\end{abstract}

Palavras-chave: Hardware. Robótica Educacional. Aprendizagem Baseada em Projetos.

\begin{abstract}
This paper describes a pedagogical approach to the teaching of computer hardware through educational robotics. For this, we used project-based learning with RE, supported by meaningful learning to make learning more dynamic and contextualized to the challenges that the future technician will have when exercising a profession. The case study showed that hardware learning can be favored with this approach besides enabling students to engage in class, promoting the development of technical, social, and emotional skills in students.
\end{abstract}

Keywords: Hardware. Educational Robotics. Project-Based Learning.

\footnotetext{
* Mestre em Informática na Educação - Mestrado Profissional em Informática na Educação. Instituto Federal de Educação, Ciência e Tecnologia do Rio Grande do Sul - Campus Porto Alegre - RS / Brasil. E-mail: marcos.corino@veranopolis.ifrs.edu.br. Orcid: https://orcid.org/0000-0002-4739-2019.

** Doutora em Computação pela Universidade Federal do Rio Grande do Sul (2004). Professora Orientadora Mestrado Profissional em Informática na Educação. Instituto Federal de Educação, Ciência e Tecnologia do Rio Grande do Sul - Campus Porto Alegre - RS / Brasil. E-mail: silvia.bertagnolli@poa.ifrs.edu.br. Orcid: https://orcid.org/0000-0001-7495-6636.

*** Doutor em Informática na Educação. Professor do Mestrado Profissional em Informática na Educação do Instituto Federal de Educação, Ciência e Tecnologia do Rio Grande do Sul - Campus Porto Alegre - RS / Brasil. E-mail: marcelo.schmitt@poa.ifrs.edu.br. Orcid: https://orcid.org/0000-0003-1290-5029.
} 


\section{Introdução}

Atualmente, todo usuário interage com o software (através de mouse, teclado, câmera, microfone, tela sensível ao toque, etc.) e este, por sua vez, interage com o hardware de modo que as informações sejam devidamente processadas. Conforme argumentam Raabe et al. (2017) "compreender como a informação é processada por computadores e os diferentes níveis de relação entre hardware e software" é um dos pilares do mundo digital. Os mesmos autores ainda apontam como uma das habilidades relacionadas ao ensino de computação na educação básica "Compreender em um nível detalhado a relação entre hardware e software (camadas/sistema operacional) para um uso competente e eficaz do computador".

O catálogo nacional de cursos técnicos do Ministério da Educação (MEC), estabelece que alguns dos cursos técnicos do eixo de Informação e Comunicação, sejam eles integrados ou subsequentes ao ensino médio, devem propiciar que estudantes matriculados compreendam os componentes que compõem um computador; e sejam capazes de montar/desmontar, configurar e instalar softwares (MEC, 2016).

Para o ensino efetivo de hardware em sala de aula são necessários alguns equipamentos específicos, ou a disponibilidade de um laboratório próprio para este fim. As instituições, normalmente, não possuem os equipamentos mínimos necessários para o aprendizado de hardware, devido ao seu alto custo e dos materiais e equipamentos necessários para uma prática eficaz. (SANTOS, 2013). Estudos relacionados com tecnologias para o ensino de hardware de computadores apresentam como problemáticas: a ênfase de aulas com exposição predominantemente teórica, fato decorrente da falta de infraestrutura, aparato tecnológico, equipamentos obsoletos e alto custo operacional de laboratórios específicos (DAMASCENO; DAMASCENO, 2013; DAMASCENO; OLIVEIRA, 2013; PRASAD et al., 2015; SARKAR; CRAIG, 2007).

Assim, cabe à instituição ou ao docente identificar alternativas pedagógicas que possam potencialmente reduzir alguns desses problemas, e ainda favorecer uma aprendizagem baseada na colaboração e cooperação entre os estudantes e guiada por um docente. A partir de uma revisão sistemática da literatura e de uma pesquisa exploratória foi possível verificar quais abordagens e tecnologias poderiam ser utilizadas para o ensino de hardware, com o propósito de tornar as aulas mais práticas, atrativas, oportunizando aos alunos o desenvolvimento das competências necessárias para o mundo moderno.

Para o contexto deste artigo, delimitou-se a robótica educacional integrada à metodologia de Aprendizagem Baseada em Projetos (ABP), para propiciar uma aquisição do conhecimento mais autônoma e contextualizada de Hardware, como uma estratégia para integrar a teoria e a prática, e potencializar a aprendizagem dos estudantes. No caso deste trabalho, optou-se por restringir a pesquisa ao curso técnico em informática, do Campus Avançado Veranópolis, do Instituto Federal de Educação Ciência e Tecnologia do Rio Grande do Sul (IFRS), adotando-se uma pesquisa ação como procedimento metodológico. (FILIPPO; ROQUE; PEDROSA, 2019).

A educação profissional oferece muitas oportunidades para aplicar metodologias ativas de aprendizagem nas diferentes áreas de formação profissional. É o caso das aulas de laboratório, que promovem a participação e o envolvimento dos estudantes no processo de aprendizagem (BARBOSA; MOURA, 2013) Neste sentido, a aprendizagem baseada em projetos, busca envolver os alunos na aquisição de conhecimentos e competências utilizando projetos reais e efetivos, possibilitando a investigação de problemas ou tarefas reais, que sejam motivadores e atrativos, com o intuito de se obter uma aprendizagem eficiente e eficaz (BENDER, 2014; JOCELEN et al., 2012). 
A utilização de Robótica Educacional (RE) aliada a projetos interdisciplinares mostrase uma excelente forma de "engajar os estudantes no conhecimento, na vivência e na mudança de um mundo complexo e em rápida transformação" (BACICH; MORAN, 2018, p. 12). Isso porque, a RE tem possibilitado através dos dispositivos robóticos, trabalhar conceitos por meio de atividades que propiciam a investigação, o protagonismo e a autonomia do aluno em seu processo de aprendizagem. Para incentivar ainda mais a efetividade da proposição pedagógica, os estudos foram ancorados nos pressupostos teóricos da aprendizagem significativa de Ausubel (2000), a qual estabelece que o processo de aprendizagem deve levar em conta os conhecimentos prévios do estudante. Assim, é possível determinar quais conceitos devam ser abordados e de que forma os novos conteúdos serão trabalhados, com o foco nas relações que o aluno deve ser capaz de estabelecer.

O artigo prossegue organizado em nove seções: as seções 2, 3 e 4 apresentam aspectos teóricos que embasaram o desenvolvimento deste trabalho; a seção 5 detalha a metodologia empregada, com descrição das fases do trabalho, métodos, materiais e técnicas utilizadas durante a pesquisa; a seção 6 apresenta como a ABP foi utilizada neste estudo. A seção 7 descreve as atividades desenvolvidas; e, na seção 8, são demonstrados os resultados obtidos com a pesquisa; e, para encerrar, a seção 9 traz algumas das conclusões baseadas nos objetivos e resultados do trabalho.

\section{$2 \mathrm{O}$ ensino de hardware de computadores}

As tecnologias de hardware estão em evolução contínua, o que torna cada vez mais difícil acompanhar os avanços tecnológicos, este fato tem elevado o grau de dificuldade de quem trabalha ou quer ter um conhecimento sobre os novos dispositivos, componentes e tecnologias que compõem o computador (DAMASCENO; DAMASCENO, 2013). Alguns estudos mostram que a falta de atividades práticas em uma disciplina de hardware é apontada como uma das maiores adversidades para o seu desenvolvimento, uma vez que o ensino se torna subjetivo demais, distanciando-se da realidade. Torna-se improdutivo ensinar conceitos de hardware se os métodos se concentrarem apenas nos aspectos teóricos, pois é necessário para o aprendizado que os alunos interliguem a teoria à experiência prática (PRASAD et al., 2015). A abstração causada pela exposição teórica desses conceitos leva à desmotivação e à redução do nível de aprendizagem do aluno (SARKAR; CRAIG, 2007).

Como alternativa aos problemas expostos anteriormente, os trabalhos que abordam o ensino de hardware trazem o uso de ambientes virtuais ou simuladores. Eles buscam, por meio desses, a interação do aluno com ambiente tridimensional, procurando convencê-lo da veracidade do Ambiente Virtual (AV) mediante o contato entre homem e máquina (MENDEZ et al., 2018; PRASAD et al., 2015; SANTOS, 2013). Em outra linha de pesquisa, os trabalhos expõem a realidade aumentada como uma forma de interação que pode dar ao aluno "uma noção visual do funcionamento interno de uma organização de computador pode tornar o aprendizado mais divertido e motivador para o aluno, auxiliando no seu entendimento" (BRUM; PINHO; CAMARGO, 2015, 2017; MARTINS et al., 2014). Os estudos de Calazans e Moraes (2001); Dobgenski (2008) e Sarkar e Craig (2007) utilizam componentes físicos como FPGA (Field Programmable Gate Array, em português Arranjo de Portas Programáveis em Campo), CPLD

(Complex Programmable Logic Device, em português Dispositivo Lógico Complexo Programável) e PIC (Programmable Interface Controller, em português Controlador de Interface Programável) para o ensino de hardware. De acordo com (DOBGENSKI, 2008), a utilização de microcontroladores facilitou a realização de projetos interdisciplinares e 
possibilitou ao aluno empregar os conhecimentos adquiridos nas disciplinas de hardware, software e redes.

\section{Robótica educacional}

A robótica educacional tem sido utilizada como uma importante ferramenta para o desenvolvimento cognitivo e de habilidades sociais de alunos nos diversos níveis de educação, embasando o aprendizado de Ciências, Matemática, Tecnologia, Computação e outros saberes (CAMPOS, 2017). Conceituada como a (re)utilização de aspectos da robótica industrial, na sala de aula, ela tem como objetivo "promover o estudo de conceitos multidisciplinares, como física, matemática, geografia, português, informática, entre outros" (TORCATO, 2012, p. 2). A Robótica Educacional, “[...] estimula a criatividade dos alunos devido a sua natureza dinâmica, interativa e até mesmo lúdica além de servir de motivador para estimular o interesse dos alunos no ensino tradicional." (GOMES, 2007, p. 130).

Ao empregar a RE em sala de aula o professor propicia o planejamento de atividades em grupo e o desenvolvimento de competências no uso de tecnologias. Neste sentido, Fornaza (2016) afirma que a RE contribui para o desenvolvimento da criatividade e de habilidades no aluno, utilizando-se de diversos materiais (motores e sensores controlados por um microcontrolador, que pode ser programado para o funcionamento de acordo com os protótipos montados), disponibiliza aos alunos um mecanismo para criar soluções vinculadas com a realidade, tornando o aprendizado dinâmico e estimulante, isso porque oferece ao aluno a chance de desenvolver sua criatividade através da elaboração de seu próprio protótipo. (NASCIMENTO, 2014). Nesta perspectiva, de acordo com Costa Junior (2017), o uso da RE possibilita situações de ensino e aprendizagem eficazes na integração de conceitos, fenômenos físicos, sensores, motores e programação (COSTA JUNIOR, 2017).

\section{A abordagem pedagógica}

Para que a aprendizagem seja significativa é preciso que o aluno seja capaz de relacionar o que está sendo apresentado com algo que ele já saiba, e ser capaz de reproduzi-lo com suas próprias palavras, ou com sinônimos, que expressem a ideia central. Além disso, o estudante deve relacionar o novo conceito com algum conhecimento relevante, que está presente na sua estrutura cognitiva. O conhecimento pré-existente, o qual David Ausubel (2000) denominou de subsunçor, permite que o aluno estabeleça significados às novas ideias. A utilização de materiais introdutórios mais abrangentes, generalizados e abstratos facilita o desenvolvimento dos subsunçores, e podem demonstrar a relação entre o novo conhecimento e os pré-existentes (MOREIRA, 2012).

Essa aprendizagem pode se tornar mais significativa ao ser combinada com metodologias ativas de aprendizagem, uma vez que elas proporcionam aos alunos uma maior segurança ao utilizar o que aprenderam em aplicações reais, assim como em suas decisões. Elas também aprimoram o relacionamento entre os pares, os quais aprendem a se comunicar com mais êxito, tanto de forma escrita, quanto na oral. Com elas, os estudantes alcançam aptidão para resolver problemas e experimentar circunstâncias que demandam a tomada de decisão, o que resulta no desenvolvimento da autonomia no pensar e no atuar (MARÇAL et al., 2009). A adoção de uma metodologia de aprendizagem ativa coloca o aluno como personagem principal, potencializando o seu comprometimento, a sua participação e a sua reflexão durante as etapas da aprendizagem. Além disso, ela viabiliza desenvolver um conhecimento mais amplo das 
habilidades socioemocionais, bem como de sua aplicabilidade em novas práticas (MORAN, 2013).

Entre essas metodologias, destaca-se a aprendizagem baseada em projetos, que visa envolver os alunos na aquisição de conhecimentos e competências, utilizando projetos reais e efetivos, que relacionam os conceitos e princípios centrais de uma disciplina, enfatizando pontos provocativos vinculados a um problema, uma necessidade, uma oportunidade ou a interesses de organizações (BARBOSA; MOURA, 2013). O desenvolvimento do projeto deve também demandar a utilização de ferramentas e habilidades essenciais, incluindo tecnologias para aprendizagem, autogestão e gestão do projeto, além de especificar produtos que resolvam problemas, incluindo múltiplos produtos que permitam o feedback (BUCK INSTITUTE FOR EDUCATION, 2008).

O desenvolvimento de um projeto envolve os estudantes em uma sequência complexa de tarefas, as quais demandam planejamento e organização, para que possam resultar em uma solução para o problema. Para isso é fundamental dividir responsabilidades e tomar decisões cooperativamente (BENDER, 2014). Com a utilização desse método, procura-se estruturar, motivar e enriquecer a estratégia pedagógica, assim como o processo criativo, com a finalidade de que os estudantes possam atingir melhores resultados na aprendizagem e nos seus projetos (MEURER, 2014).

Ao desenvolver um projeto é preciso ter em mente que esse deve gerar um produto final para atender ao objetivo inicial, refletir o trabalho realizado e demonstrar a aprendizagem durante a sua operacionalização (BENDER, 2014). Neste sentido, o uso da RE permite que os alunos solucionem problemas, desenvolvam o raciocínio lógico e construam o trabalho em pares ou grupos, com respeito mútuo (BORGES; FAGUNDES, 2016). Desta forma, os alunos procuram construir de forma coletiva o conhecimento interdisciplinar, por meio do protagonismo e aprendem fazendo em cooperação com os colegas. Assim, os alunos precisam planejar as ações de sua equipe conforme avançam na solução do problema, criando um plano de ação e começando a conceber o esboço para o desenvolvimento de seus produtos (OLIVEIRA, 2018).

O uso de projetos integradores (interdisciplinares) constitui um grau mais avançado de execução de projetos, uma vez que integra mais de uma disciplina, professores e áreas de conhecimento, o que contribui para que os alunos possam compreender melhor as ligações implícitas entre as disciplinas. Como os projetos se aproximam da vida e do entorno dos alunos, eles devem ter origem a partir de problemas concretos, mostrando uma perspectiva importante da aprendizagem atua. Neste tipo de aprendizagem, alunos e professores, convivem com grupos variados, conhecem a realidade, e, simultaneamente, aprendem com elas e contribuem com soluções concretas para melhorar a vida de uma comunidade (BACICH; MORAN, 2018). Se o projeto promover atividades que propiciem ao aluno ouvir, ver, perguntar, discutir, fazer e ensinar, a aprendizagem ativa está acontecendo (BARBOSA; MOURA, 2013).

\section{Procedimentos Metodológicos}

O procedimento metodológico principal selecionado para o desenvolvimento do presente trabalho foi a pesquisa-ação, a qual foi organizada seguindo o ciclo definido por Filippo, Roque e Pedrosa (2019), que é estruturada da seguinte forma: etapa 1 - planejar, identificar problema, propor solução e preparar ação; etapa 2 - agir, composta pelas fases implementar e aplicar a solução, e observar o ambiente; etapa 3 - refletir, sistematizada nas fases avaliar resultados, relacionar com a teoria e publicar conhecimento. 
A pesquisa iniciou-se com uma revisão sistemática da literatura, em que foram identificados trabalhos, no período de 2015 a 2018, que abordassem a temática do ensino de hardware nos mais diversos níveis de ensino, bem como as estratégias pedagógicas adotadas para este fim. As buscas de trabalhos relacionados foram conduzidas em anais de eventos, workshops, periódicos científicos e congressos da Sociedade Brasileira de Computação (SBC), assim como em portais de teses e dissertações. O levantamento inicial se deu através dos títulos de trabalhos publicados nos locais pesquisados. Para isso, empregou-se as seguintes strings de busca: ensino, robótica educacional, aprendizagem significativa, aprendizagem baseada em projetos e objetos de aprendizagem, todas combinadas com o termo "hardware".

A partir dessa procura, foi possível observar que a maioria dos trabalhos aplicava ambientes virtuais ou simuladores como estratégia pedagógica. Após essa etapa, foram realizadas entrevistas semiestruturadas com estudantes, de modo a identificar as suas percepções sobre o problema pesquisado. Uma pesquisa documental foi realizada para identificar os conteúdos de hardware, que, geralmente, são trabalhados nos cursos de informática. Além disso, foi realizada uma análise detalhada das matrizes curriculares e dos planos de ensino dos seus componentes curriculares, presentes nos Projetos Pedagógicos dos Cursos Técnicos do eixo de Informação e Comunicação, operacionalizados no âmbito do IFRS.

Nessa investigação, foi possível mapear os conteúdos trabalhados e generalizá-los sob um conceito comum mais amplo e genérico, a fim de identificar e remover duplicidades oriundas de nomenclaturas diferentes. Com esse mapeamento, foi possível determinar os conteúdos abordados nos cursos e determinar quais poderiam ser trabalhados com RE. Seguindo a teoria da aprendizagem de Ausubel (2000) e Moreira (1999) foi desenvolvido o Mapa conceitual que possibilitou sistematizar, de forma hierárquica, os conteúdos de hardware presente nos Projetos Pedagógicos dos Cursos (PPCs) analisados (Figura 1), e os possíveis de serem trabalhados por meio da RE, os quais estão ilustrados em verde na Figura 2.

Figura 1 - Mapa conceitual dos conteúdos de hardware

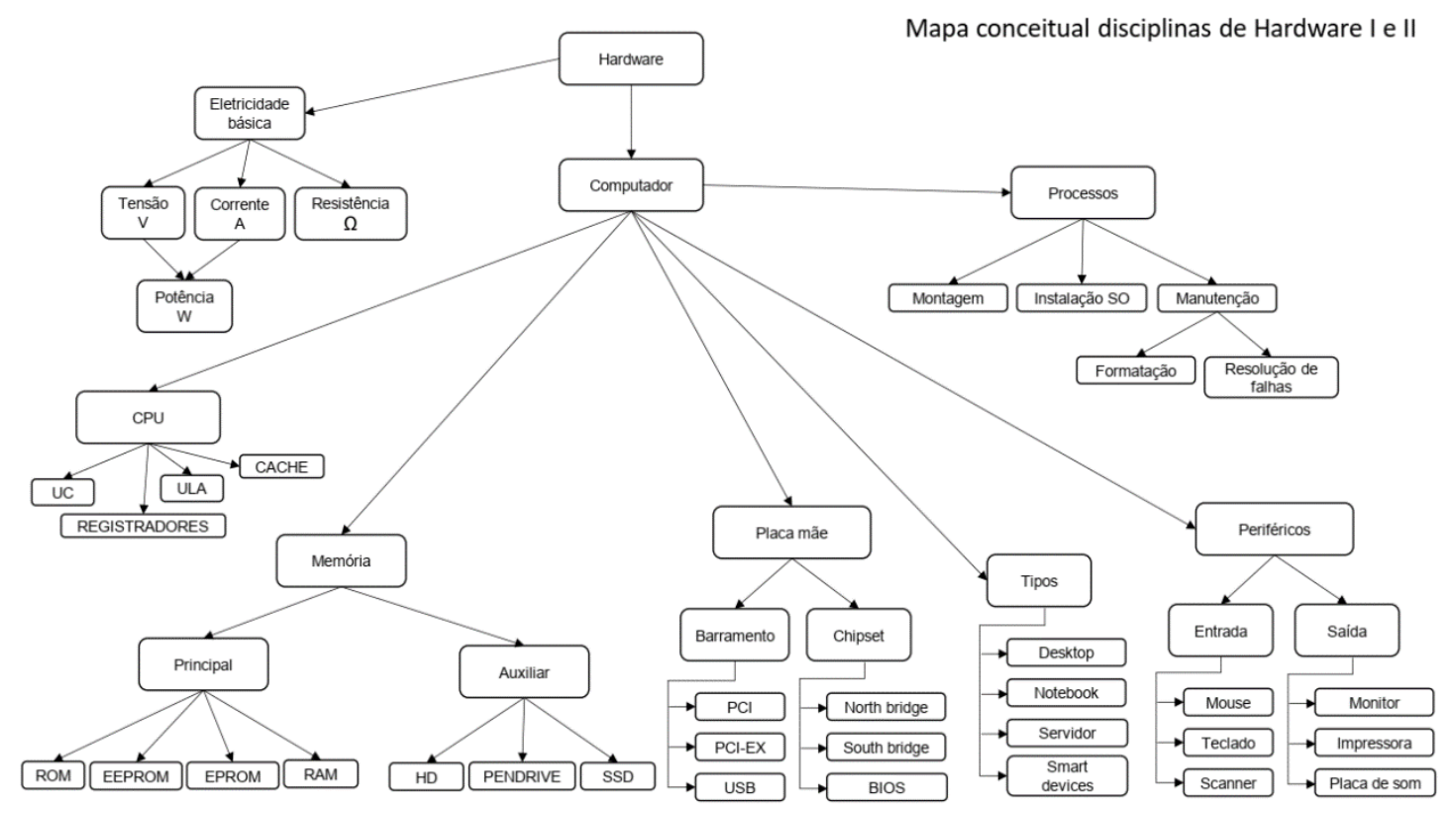

Fonte: Elaborado pelo(s) autor(es), 2019. 


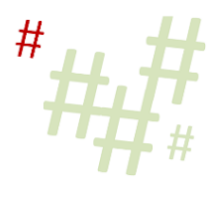

Figura 2 - Mapa conceitual dos conteúdos trabalhados com RE

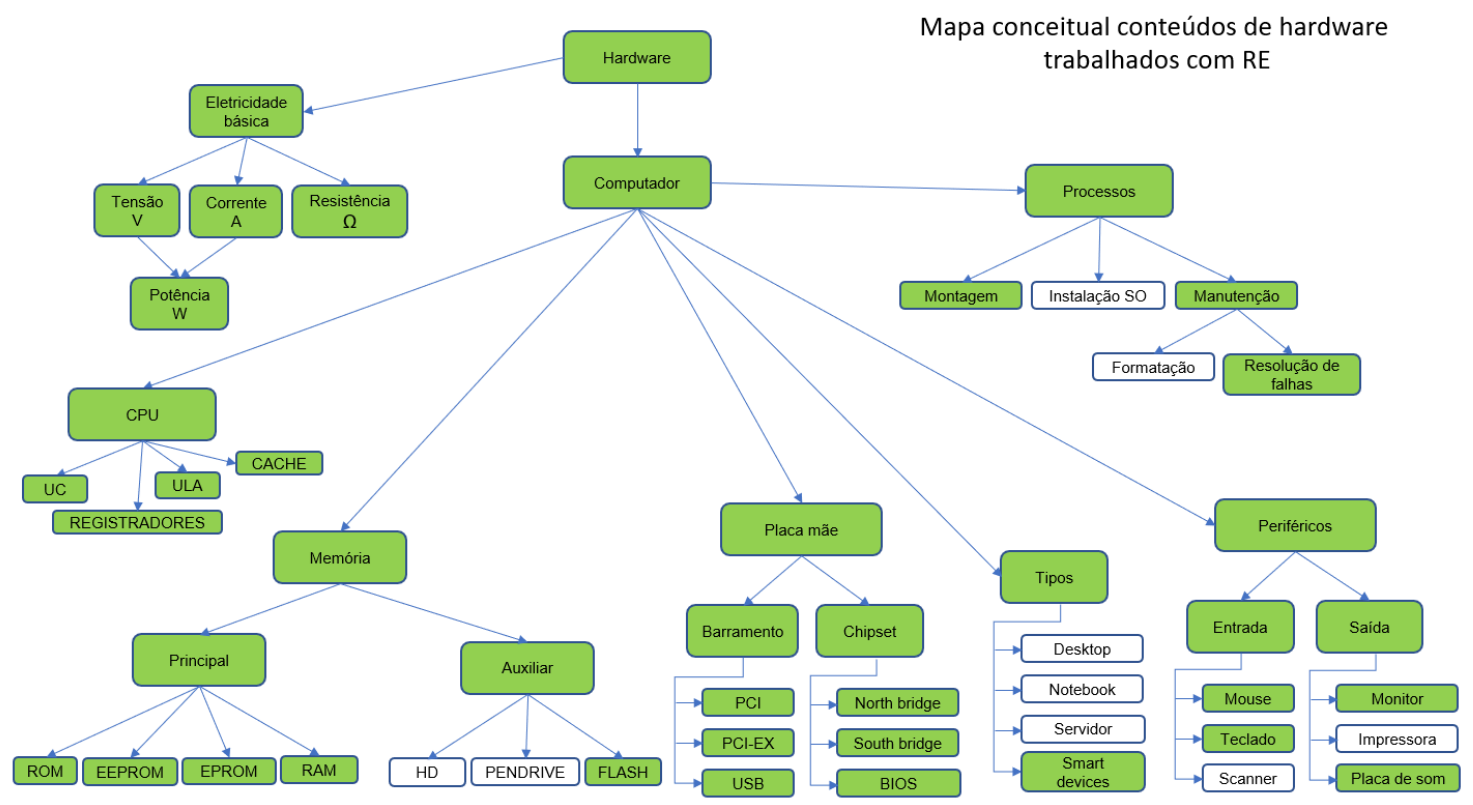

Fonte: Elaborado pelo(s) autor(es), 2019.

A solução, descrita neste trabalho, utiliza-se de dispositivos robóticos aliados à aprendizagem baseada em projetos, para abordar, de forma prática, os tópicos de hardware de computadores em um curso de Informática. Desta forma, foram utilizados a plataforma Arduino e diversos módulos para representar os conceitos semelhantes aos de hardware, visando estabelecer uma correlação.

Para validar a proposta, foi necessário estabelecer quem seriam os participantes da pesquisa. Assim, delimitou-se como participantes desta pesquisa alunos do curso Técnico em Informática Subsequente ao Ensino Médio do Campus Avançado Veranópolis do IFRS. A turma era composta por 14 alunos matriculados, com $73 \%$ homens e $27 \%$ mulheres, distribuídos em três cidades da região com até $20 \mathrm{~km}$ de distância do Campus, sendo que apenas $20 \%$ exercem atividades na área do curso, o que favoreceu o desenvolvimento e a avaliação da presente pesquisa.

Considerando a segunda etapa do ciclo relativo à pesquisa-ação (FILIPPO; ROQUE; PEDROSA, 2019), e os fundamentos da teoria de Ausubel (2000), foi aplicado um questionário com perguntas sobre os conteúdos previamente estudados, de modo a identificar quais seriam os organizadores prévios dos estudantes. E, ao concluir essa atividade, outro questionário foi aplicado, o qual viabilizou perceber a evolução dos estudantes nessa pesquisa. Esses questionários possibilitaram abordar os conhecimentos básicos que seriam necessários para o desenvolvimento do projeto. Com base na análise das suas questões, foi possível verificar o nível de conhecimento inicial dos indivíduos. As informações serviram de entrada para o planejamento das aulas, a para a sistematização dos conteúdos de robótica educacional, os quais foram desenvolvidos de forma correlacionada aos temas de hardware. Destaca-se que também foram definidos materiais introdutórios sobre o tema para facilitar a aprendizagem significativa, conforme estabelece a teoria de Ausubel (2000).

Como essa pesquisa tem caráter qualitativo, busca-se a compreensão do fenômeno em estudo sem preocupação com representatividade numérica, generalizações estatísticas e relações lineares de causa e efeito (GUERRA, 2014). Foi realizada uma Análise de Conteúdo 
Temática para a interpretação do material qualitativo, o que proporcionou uma descrição objetiva, sistemática dos dados. Esse método ocorreu em três etapas: pré-análise, exploração do material e tratamento dos resultados (GUERRA, 2014). Seguindo essas etapas, as questões do pré-teste e do pós-teste foram agrupadas sob categorias de acordo com o assunto abordado e a uma categoria geral. Durante a exploração do material, foram contabilizados os erros e acertos dos alunos em cada categoria. Ainda, foram cruzados os números obtidos do teste inicial com o final. Para deduzir os resultados deste estudo, foram utilizadas a variação de acertos por conteúdo, divididos em geral e por aluno, assim como a variação de acertos por área e geral da turma. Os dados foram gerados e coletados a partir da aplicação de testes com perguntas abertas e fechadas em dois momentos distintos.

Para a realização do estudo, foram destinadas cinco aulas para a abordagem de hardware, conforme o planejamento definido na etapa anterior. Para favorecer a aprendizagem e estimular a diferenciação progressiva, as práticas pedagógicas foram organizadas de forma que os conceitos-chave da disciplina fossem apresentados nas primeiras aulas e, gradativamente, particularizados, apontando suas diferenças, semelhanças e distinções no decorrer das demais aulas, para que assim a reconciliação integrativa pudesse beneficiar o processo (AUSUBEL, 2000). Dessa forma, os conceitos eram apresentados utilizando-se de revisões de conteúdos que já haviam sido abordados nas disciplinas de hardware de computadores, e, vinculando-os com os temas apropriados da robótica educacional, para que o aluno fosse capaz de compreender como eles se correlacionam.

Com o objetivo de organizar e possibilitar o acompanhamento das atividades do projeto, foi adotado o método "Kanban", o qual permite identificar e promover a divisão do trabalho, visando a conclusão de uma tarefa. Ele ainda possibilita a visualização das tarefas em andamento, dentro das etapas, e a delimitação de tarefas realizadas simultaneamente em cada etapa do processo, para que se tenha um ritmo constante de execução do projeto (PEINADO; GRAEML, 2007). O uso do Kanban permite que haja uma maior compreensão do escopo do projeto, além de possibilitar que os processos sejam mais visuais, tornando mais fácil a identificação de possíveis falhas (MONTEIRO; PINTO; DOS SANTOS, 2012).

Considerando a terceira etapa da pesquisa-ação, foi necessário avaliar e refletir sobre as intervenções realizadas, os objetivos alcançados e as transformações ocorridas (FILIPPO; ROQUE; PEDROSA, 2019). Com o intuito de ter uma visão ampla do processo e ter uma coleta contínua de dados, foram utilizados os pré-testes para avaliar o processo de aprendizagem, as anotações do método Kanban dos alunos, as observações do docente e também questionários realizados com os alunos ao final do processo. Com todo esse material, foi possível identificar e corrigir erros durante o processo de intervenção, assim como pontos que precisam ser aprimorados para uma próxima abordagem.

\section{As origens do projeto}

Durante o planejamento desta pesquisa, buscou-se diversos tópicos que pudessem servir de âncora e contemplar os objetivos deste estudo. Neste mesmo período, o Campus Avançado Veranópolis iniciou a implantação de um Curso Técnico Integrado ao Ensino Médio. Assim, pensou-se em desenvolver um objeto físico como resultado do projeto, que, posteriormente, pudesse ser utilizado para atividades de ensino e aprendizagem no campus. Em uma conversa com os professores das disciplinas da base comum sobre o que poderia ajudá-los em sala de aula, o professor de física sugeriu que o produto do projeto poderia ser um objeto de aprendizagem que viabilizasse o ensino de conceitos de física, especificamente, do Movimento Circular Uniforme (MCU). Assim o "produto" resultante do projeto precisaria ser capaz de 
abordar conceitos como: velocidade linear e angular, frequência, período e aceleração centrípeta, possibilitando experimentações sobre esses fenômenos.

Com a âncora do projeto definida, buscou-se um tema que fizesse parte do cotidiano dos alunos e assim foram encontrados os brinquedos de parques de diversões, mais especificamente o Chairoplane (em português, Chapéu Mexicano), ilustrado pela Figura 3. Esse brinquedo é formado por balanços pendurados em uma estrutura de um disco circular, semelhante a aba de um chapéu, sustentado por um cilindro. Seu movimento ocorre por meio de um motor elétrico que faz a estrutura girar e, assim, os balanços se abrem no ar formando um "chapéu" semelhante ao mexicano de abas largas. Quando em movimento, atuam, nesse brinquedo, as forças centrípeta e centrífuga, que mantém o movimento circular e elevam as suas cadeiras.

Figura 3 - Chapéu mexicano real

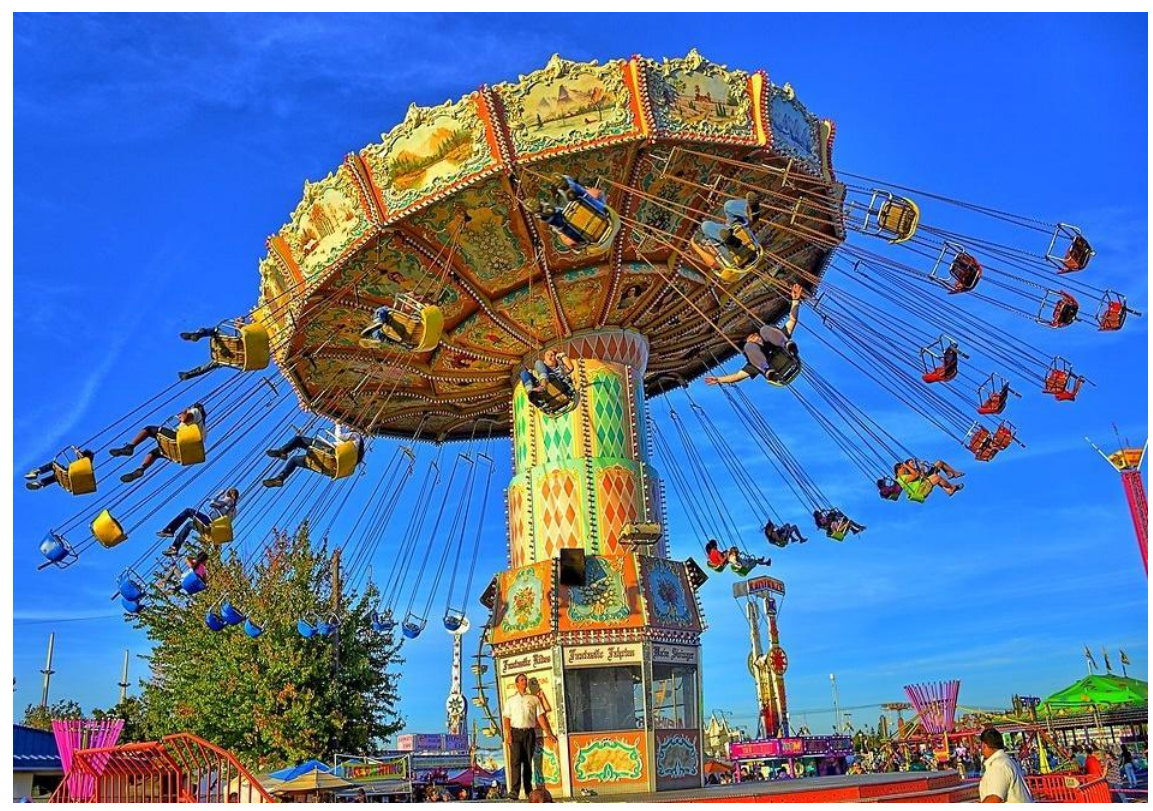

Fonte: Kirt Edblom, 2015.

O objetivo do artefato "Chapéu Mexicano" consiste em efetuar cálculos e exibir as informações sobre a variação dos fenômenos do MCU. Desse modo, para o desenvolvimento do projeto, os alunos deveriam implementar as funções solicitadas e apresentar um produto capaz de demonstrar as experimentações acerca desse movimento no display do equipamento. Para isso, no âmbito de hardware de computadores foram trabalhados, de forma prática, os conceitos de eletricidade e eletrônica básica, composição de um sistema computacional, memórias, processadores, dispositivos de entrada e saída, fontes de alimentação e sistemas de refrigeração. Quanto às outras disciplinas, foi necessário empregar conhecimentos de algoritmos e programação em linguagem $\mathrm{C}$, demonstrando, assim, a interdisciplinaridade do projeto. Com a resolução do desafio proposto, os alunos conseguiram praticar e aperfeiçoar a aprendizagem dos tópicos de hardware de computadores trabalhados.

Ao definir o objeto que seria desenvolvido, ele foi projetado, prototipado e fabricado em laboratórios do IFRS. Os protótipos foram fabricados dentro dos laboratórios PoALab e MIGRALab, os quais têm como foco utilizar recursos da Cultura Maker, Inteligência Artificial, Jogos e Robótica Educacional como instrumentos para favorecer a aprendizagem. Para a fabricação das peças, foi usado Medium-Density Fiberboard (MDF) de 3mm devido ao custo 
acessível e à leveza do material. O corte do MDF foi realizado em máquina Computer Numeric Control (CNC) de corte a laser. Já os itens tridimensionais foram confeccionados através de impressão com filamento Acrilonitrila Butadieno Estireno (ABS) por produzir itens mais resistentes e com leve flexibilidade, tornando-o ideal para processos de encaixe em sua montagem.

Os componentes utilizados foram escolhidos de forma que permitissem abordar conceitos básicos de hardware. O Arduino, por ser um pequeno microcontrolador, permite programar para processar entradas e saídas entre ele e os componentes conectados (MCROBERTS, 2011). No caso deste trabalho, foi selecionada a placa Arduino Uno, pois possui um bom número de entradas e saídas de uso geral (GPIOs - General Purpose Input/output) que podem ser programadas para fornecer uma interface entre os periféricos e o Arduino. Outro fator levado em consideração é que essa placa já estava disponível no laboratório. Além do Arduino, foram selecionados outros componentes que permitem controlar a velocidade e a direção de motores usados no objeto construído (OLIVEIRA, 2017).

\section{Desenvolvimento das atividades}

A partir do mapeamento dos conteúdos realizado na etapa da pesquisa documental (Figuras 1 e 2), foi possível determinar os tópicos que poderiam ser trabalhados com RE. $\mathrm{O}$ Quadro 1 detalha os componentes robóticos utilizados, vinculando-os aos temas de RE com os conceitos de hardware. Para este estudo, foram destinadas cinco aulas, com quatro períodos de 50 minutos cada, totalizando aproximadamente 16 horas. Durante esse tempo, foram abordados os conceitos introdutórios de hardware de computadores e eles foram vinculados à robótica.

Para o início das atividades, os alunos responderam a um diagnóstico inicial, o qual era composto por vinte questões objetivas sobre os conceitos já estudados em outras disciplinas. Esse diagnóstico permitiu identificar os conhecimentos prévios dos alunos, as lacunas na aprendizagem e os subsunçores que os sujeitos possuíam, para que os conceitos da robótica educacional pudessem ser relacionados e ancorados às estruturas cognitivas relevantes existentes. Com a análise inicial do diagnóstico, foram produzidos os planos de aula para determinar os conceitos de robótica educacional que seriam trabalhados e vinculá-los aos temas de hardware. Nesse planejamento, os materiais utilizados para o desenvolvimento do projeto foram inseridos a cada aula, de acordo com os conteúdos de hardware que seriam trabalhados e os objetivos de cada um. Foram definidos, também, o modo de condução das atividades, as formas de avaliação que foram utilizadas, os recursos didáticos envolvidos no processo e a bibliográfica básica para o embasamento das atividades.

Como pressuposto do estudo, os pesquisadores tomaram como hipótese que, inicialmente, os conceitos de robótica educacional seriam assimilados de forma mecânica, pois o aluno dificilmente estabeleceria relações com algum conceito subsunçor. Isso porque a robótica era um assunto novo, não trabalhado em nenhuma etapa do curso. Assim, após um momento mecânico, percebeu-se que a aprendizagem se tornou significativa, pois a partir de materiais introdutórios, e com o relacionamento destes com os subsunçores existentes, foi possível criar associações dos conceitos da robótica educacional com os aspectos de hardware já conhecidos. 
Quadro 1 - Conteúdos de hardware passíveis de trabalhar com robótica educacional.

\begin{tabular}{|c|c|c|c|}
\hline Módulo & Conteúdo robótica & $\begin{array}{c}\text { Conceitos de } \\
\text { Hardware }\end{array}$ & Exemplo \\
\hline Arduino Uno & Microcontroladores & $\begin{array}{c}\text { CPU (Central Process } \\
\text { Unit), Clock } \\
\text { Memórias, } \\
\text { Energia, I/O } \\
\text { (Input/Output), } \\
\text { Sinais analógicos e } \\
\text { digitais }\end{array}$ & $\begin{array}{c}\text { Fontes de energia -Tensão, Corrente e } \\
\text { Potência. } \\
\text { Memórias Flash } \\
\text { Funções e componentes da CPU }\end{array}$ \\
\hline Ponte H L298N & $\begin{array}{l}\text { Controle de } \\
\text { motores DC }\end{array}$ & $\begin{array}{c}\text { Transistores, } \\
\text { Processadores, Fontes } \\
\text { de energia }\end{array}$ & $\begin{array}{c}\text { Composição de processadores } \\
\text { Chaveamentos } \\
\text { Reguladores de tensão }\end{array}$ \\
\hline Módulo I2C & $\begin{array}{l}\text { RTC (Real Time } \\
\text { Clock), displays, } \\
\text { sensores diversos }\end{array}$ & Barramentos Memórias & $\begin{array}{c}\text { PCI Express, USB, EPROM (Erasable } \\
\text { Programmable Read-Only Memory), } \\
\text { E2PROM (Electrically- } \\
\text { Erasable Programmable Read- } \\
\text { Only Memory) North/South Bridge }\end{array}$ \\
\hline Display 16x2 & Displays & Dispositivos de I/O & Periféricos de saída \\
\hline $\begin{array}{l}\text { Sensor Hall } \\
\text { US1881 }\end{array}$ & $\begin{array}{l}\text { Sensores } \\
\text { magnéticos }\end{array}$ & $\begin{array}{l}\text { Sistemas de } \\
\text { refrigeração } \\
\text { Dispositivos de I/O }\end{array}$ & $\begin{array}{l}\text { Coolers, dissipadores } \\
\text { Periféricos de entrada }\end{array}$ \\
\hline
\end{tabular}

Fonte: Elaborado pelo(s) autor(es), 2019.

Na primeira aula, foi explicado como as atividades seriam desenvolvidas, pois a prática pedagógica seria nova aos alunos. Foram expostos os principais pontos, como funcionaria, e, principalmente, explicou-se sobre a alteração nos papéis durante o processo de aprendizagem, para que o aluno compreendesse a importância de seu protagonismo no processo de construção do conhecimento e o professor mediando este processo. Em seguida, foi apresentada a ABP e sua aplicação na educação e como ela seria desenvolvida nas atividades. Na segunda etapa da aula, foram utilizados materiais introdutórios que apresentaram a plataforma Arduino, suas características, funcionalidades e utilizações em geral. Ao propor uma atividade básica, buscouse relacioná-la com o funcionamento de um computador. Nesta atividade, os alunos tiveram contato com a placa Arduino e alguns componentes básicos como LEDs, resistores e jumpers, além de terem contato com a Integrated Development Environment (IDE) dessa plataforma.

$\mathrm{Na}$ segunda aula, a turma foi dividida em grupos de quatro alunos, com composição livre, e, na sequência, eles foram apresentados à ferramenta Trello (sistema web para Kanban) ${ }^{1}$ que foi utilizada para a gestão do projeto (Figura 4), conheceram suas funcionalidades e a forma como essa ferramenta deveria ser utilizada no desenvolvimento da disciplina, pois um dos requisitos exigidos para a construção do projeto seria a documentação das atividades sob o método Kanban.

\footnotetext{
${ }^{1}$ Disponível em: https://trello.com/pt-BR
} 
Figura 4 - Gestão do projeto com Trello

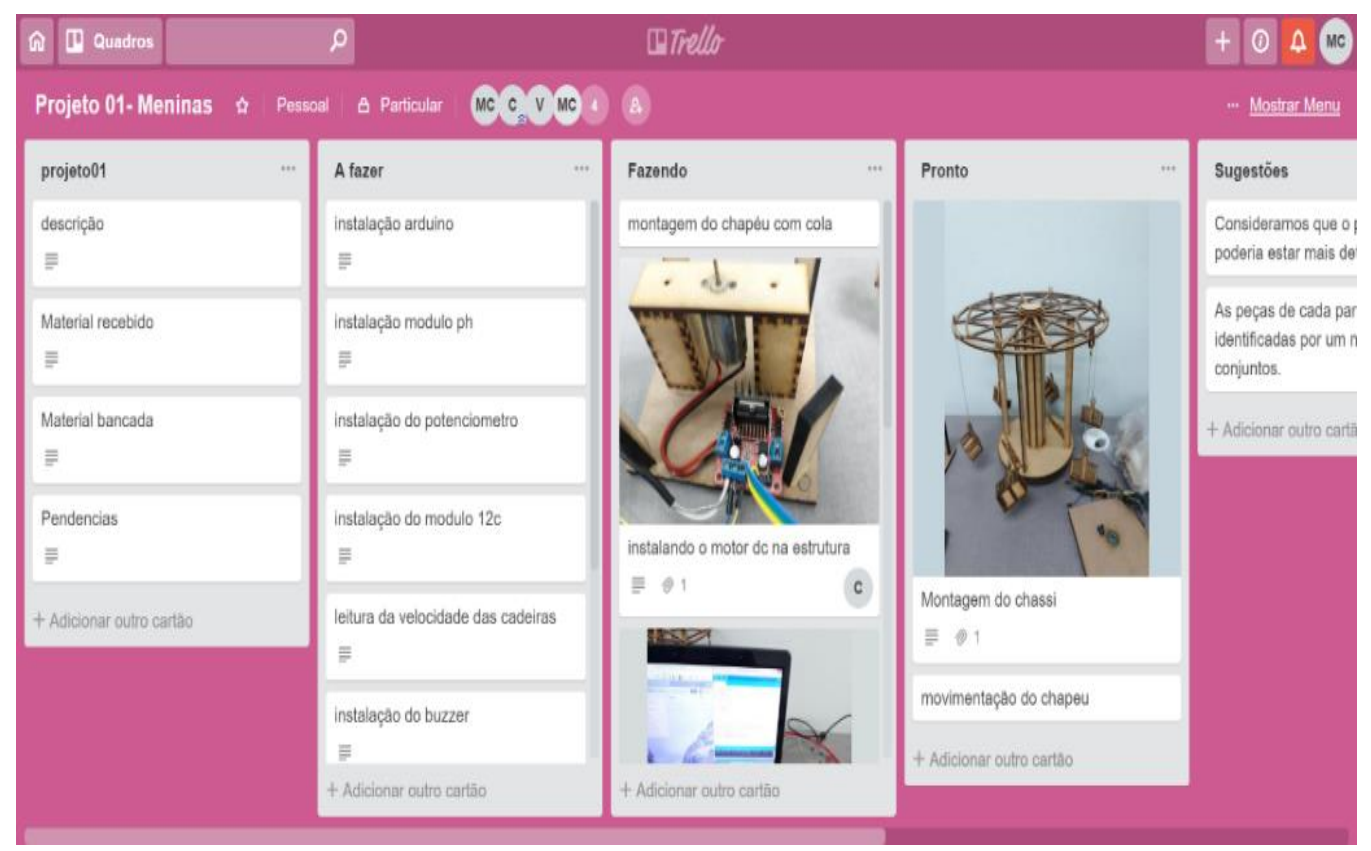

Fonte: Elaborado pelo(s) autor(es), 2019.

Em sequência, foi apresentada a questão motriz: De que formas, através da RE, podemos desenvolver uma solução para o que o chapéu mexicano seja capaz de demonstrar conceitos como: velocidade linear e angular, frequência, período e aceleração centrípeta, possibilitando experimentações sobre esses fenômenos? Para dar início ao processo de montagem estrutural foram disponibilizados guias de montagens e o guia de referência sobre os componentes que deveriam ser utilizados. Nesse guia, estão descritas as características técnicas, exemplos de uso e material de referência, para que o aluno disponha de material de consulta para o desenvolvimento dos objetivos do projeto. O conteúdo dos guias não demonstra ou estabelece uma solução, nele são listados exemplos de soluções genéricas com os materiais recebidos, distantes dos objetivos do projeto. Para alcançá-los, os estudantes precisavam realizar adaptações para o uso dos materiais, o que incentiva a autonomia e a criatividade na construção da solução. Após isso, foram distribuídos os materiais para a montagem estrutural como: cola, peças cortadas em MDF, que foram montadas de acordo com o guia de montagem.

$\mathrm{Na}$ terceira aula, os alunos receberam as ferramentas necessárias para $\mathrm{o}$ desenvolvimento do produto, entre elas ferro de solda, multímetro, protoboard, alicate de corte, jumpers de diversos tamanhos, e chaves de fenda e Philips. Em seguida, foram distribuídos os primeiros módulos: sendo apresentadas as características e funcionalidades de cada um dos itens, comparando e relacionando com tópicos de hardware. Após, foram demonstrados exemplos de uso de cada um e combinações entre eles, sem demonstrar de que forma eles poderiam ser usados no projeto. A Figura 5 ilustra as atividades realizadas na quarta aula, na qual foram adicionados novos componentes seguindo a metodologia da aula anterior. Nesta etapa, os alunos trabalharam com a leitura de dados do sensor com o Arduino e sua exibição no display LCD. A partir dessa etapa, os alunos já teriam condições de desenvolver a solução do projeto com os materiais disponibilizados. 
Figura 5 - Desenvolvimento das atividades entre os pares

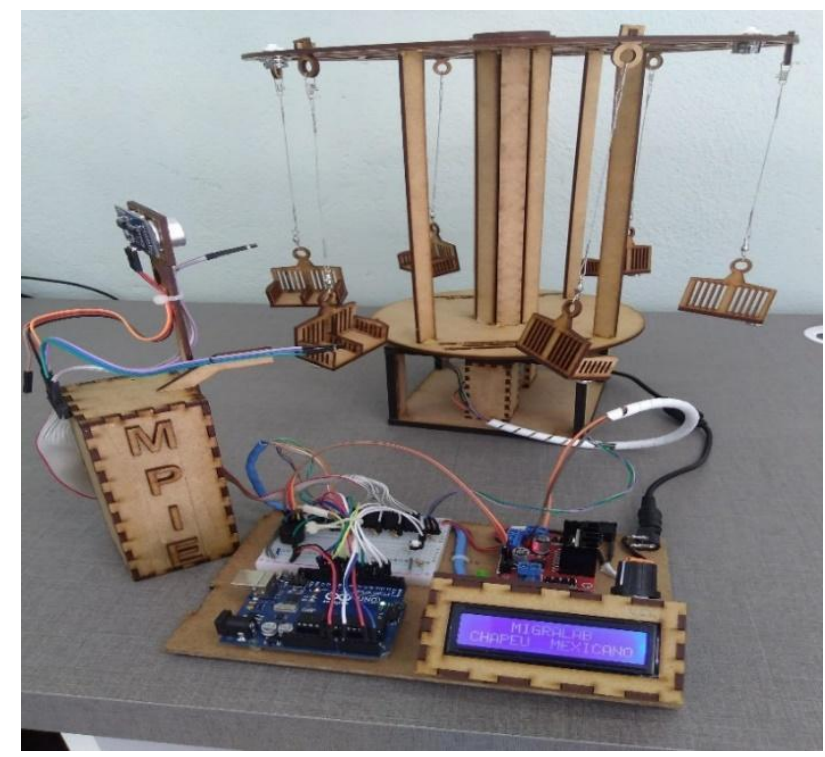

Fonte: Elaborado pelo(s) autor(es), 2019.

$\mathrm{Na}$ quinta aula, os alunos precisaram concluir e apresentar a solução desenvolvida, o Chapéu Mexicano, ilustrado pela Figura 6, capaz de demonstrar as experimentações acerca do MCU no display do equipamento.

Figura 6 - Resultado do projeto chapéu mexicano

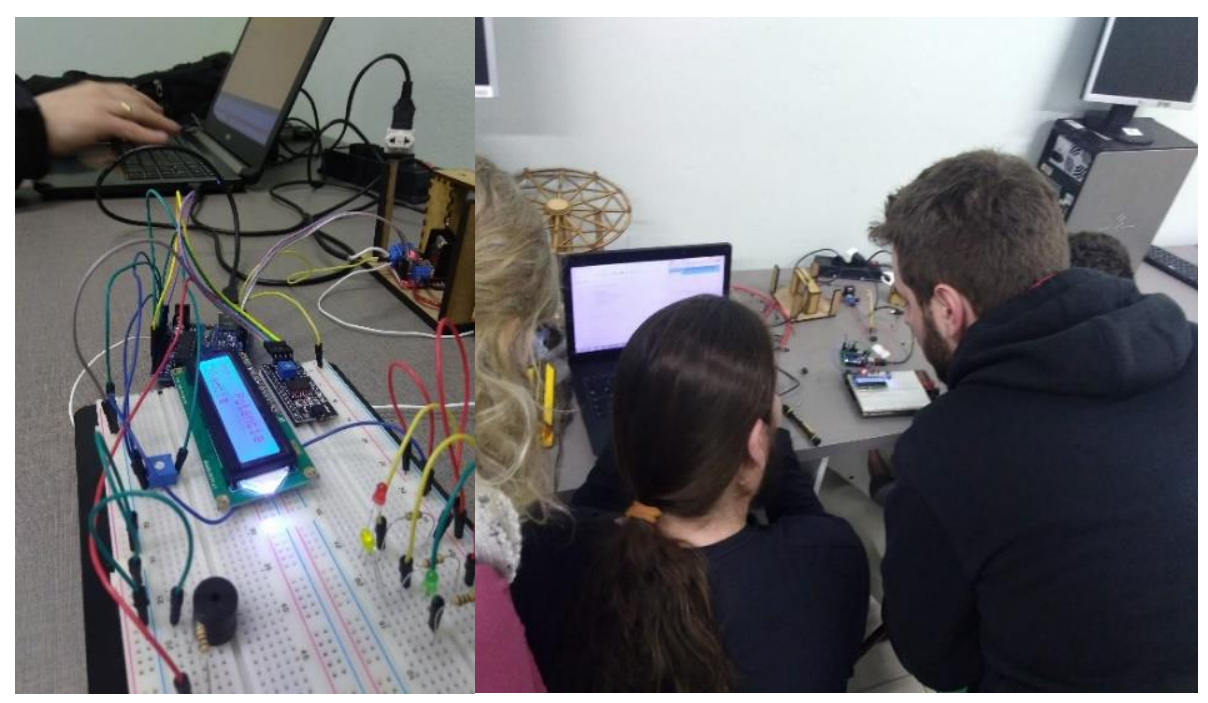

Fonte: Elaborado pelo(s) autor(es), 2019.

Na segunda etapa da aula, foi aplicado o pós-teste com 20 perguntas fechadas para avaliar o conhecimento de hardware adquirido no desenvolvimento do projeto. Os resultados obtidos com os questionários aplicados durante a pesquisa encontram-se detalhados na próxima seção. 


\section{Resultados e Discussões}

O objetivo principal deste trabalho foi avaliar o uso da robótica educacional e ABP para uma aprendizagem mais autônoma e contextualizada de tópicos de hardware. A proposta pedagógica desenvolvida na turma do curso técnico em informática mostrou-se inovadora, teve grande adesão dos alunos no desenvolvimento das atividades práticas realizadas em sala de aula. A maior parte dos alunos, 64\%, nunca tinha trabalhado com robótica antes. O desenvolvimento do projeto aconteceu de forma satisfatória, bem como o trabalho em equipe. O tema do projeto provocou a curiosidade dos alunos que buscaram conhecimento fora da sala de aula e trocaram experiências entre os grupos.

No campo da aquisição do conhecimento, os resultados seguem o que os estudos de Sarkar e Craig (2007) e Prasad et al. (2015) afirmam: a adoção de atividades práticas, nesse caso utilizando a RE, facilitaram o processo de aprendizagem, pois permitiram demonstrar aplicações práticas dos conceitos teóricos, bem como motivaram os alunos para o desenvolvimento das atividades. O aumento do nível de aprendizado, é demonstrado pelo Gráfico 1, em que o nível de conhecimento é maior no diagnóstico final em relação ao inicial. Acredita-se que as atividades desenvolvidas com a adoção dessa prática pedagógica sejam as responsáveis por esse aumento, pois, segundo os autores, quando o estudante consegue realizar ligações entre a teoria e a prática dos conteúdos estudados a produtividade do processo de aprendizagem é maior.

\section{Gráfico 1 - Relação de acertos diagnóstico inicial x final}

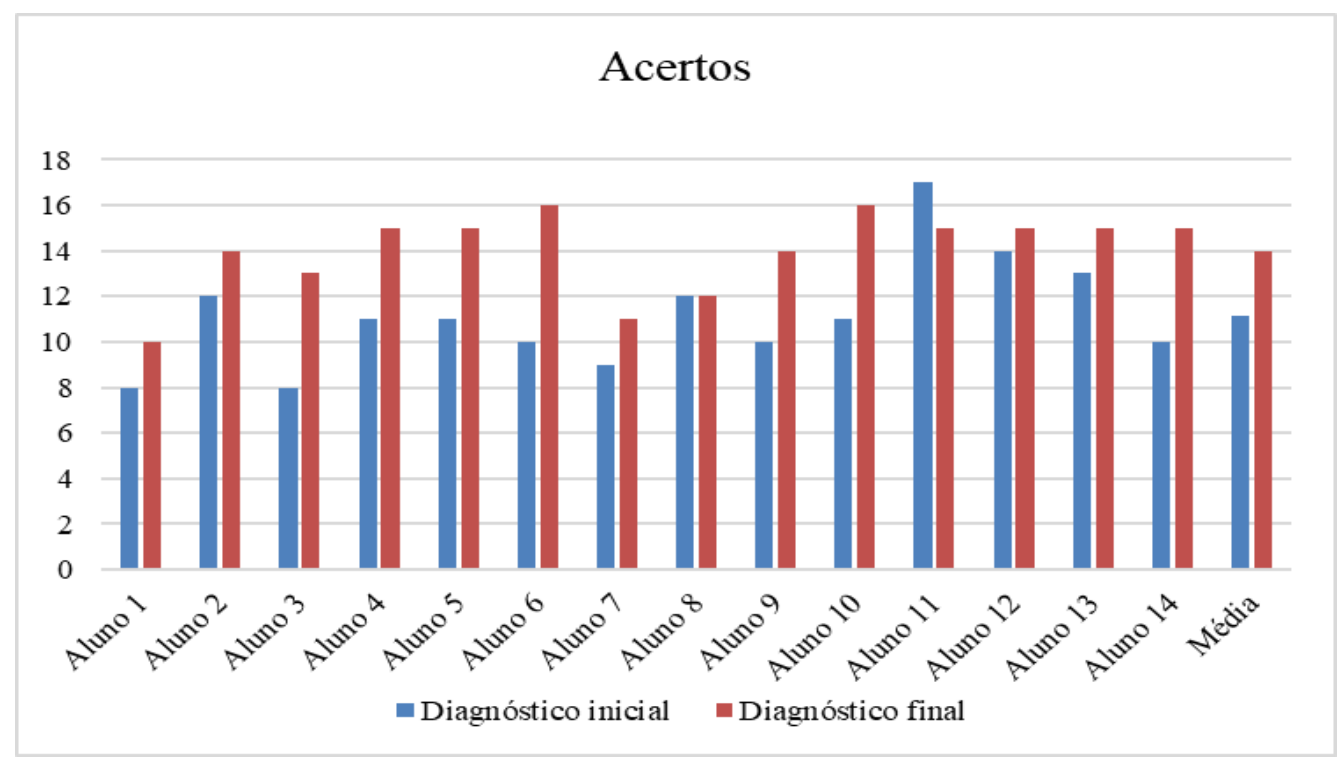

Fonte: Elaborado pelo(s) autor(es), 2019.

Os conceitos de energia, como tensão, corrente e resistência são trabalhados no ensino médio e revistos nas disciplinas introdutórias do curso. Os aspectos de programação são trabalhados no desenvolver de todo o curso e deveriam estar assimilados. Essa falta de conhecimentos prévios prejudicou a interdisciplinaridade, fato demonstrado pelo Gráfico 2, que ilustra as dificuldades citadas pelos alunos no desenvolvimento do projeto. As tarefas de programação, ainda que básicas, foram classificadas como a principal dificuldade, visto que diversas atividades demandaram codificações na plataforma Arduino, utilizando a linguagem C. 
Gráfico 2 - Dificuldades encontradas na realização do projeto

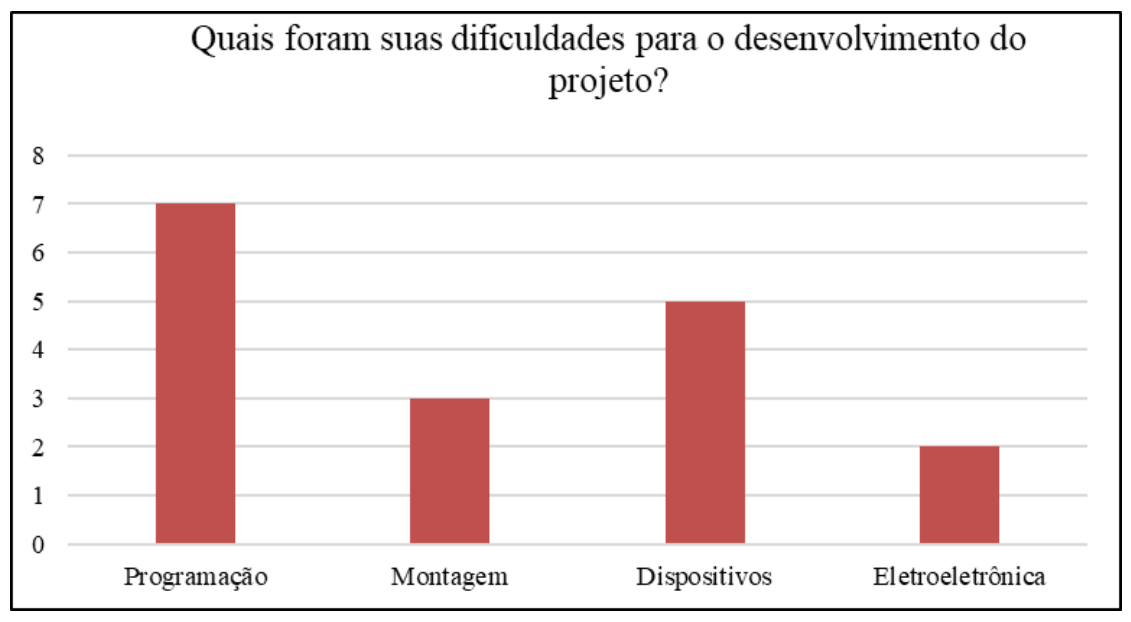

Fonte: Elaborado pelo(s) autor(es), 2019

As atividades propiciaram a troca de conhecimento e aprendizagem entre alunos, fato ilustrado pelo Gráfico 3. O uso de metodologias ativas permitiu estimular a criatividade de cada aluno, o sentimento de que todos são capazes de evoluir com as pesquisas, descobertas e realizações (BACICH; MORAN, 2018).

Gráfico 3 - Relação de acertos diagnóstico inicial x final

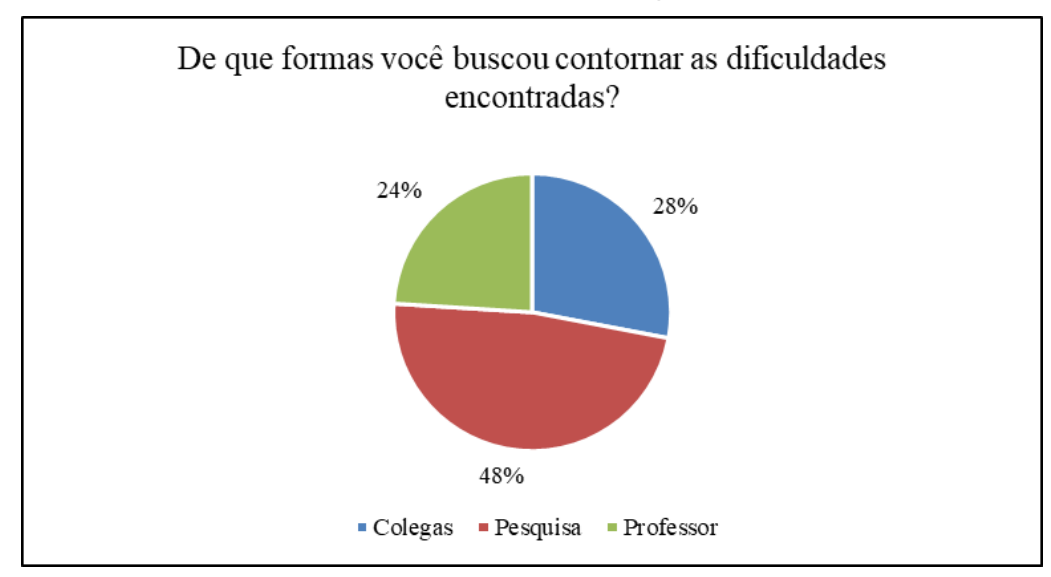

Fonte: Elaborado pelo(s) autor(es), 2019

O feedback discente trouxe informações importantes a respeito da prática pedagógica utilizada. Para os alunos, as atividades favoreceram muito a criatividade, raciocínio, colaboração e a troca de experiências entre as equipes, demonstrados pelo Gráfico 4. Quanto ao seu protagonismo e engajamento para o desenvolvimento do projeto, os alunos classificaram as atividades como adequadas. O feedback dos alunos ratifica que o uso da robótica educacional, em sala de aula, faz com que o aluno não apenas utilize um dispositivo tecnológico, mas tenha em mãos uma ferramenta que permite o desenvolvimento de habilidades como o trabalho em equipe, a resolução de problemas e o aprendizado de conteúdos relacionados a outras áreas (GUARENTI, 2015). 
Revista de Educação, Ciência e Tecnologia

Gráfico 4 - Avaliação discente das atividades desenvolvidas

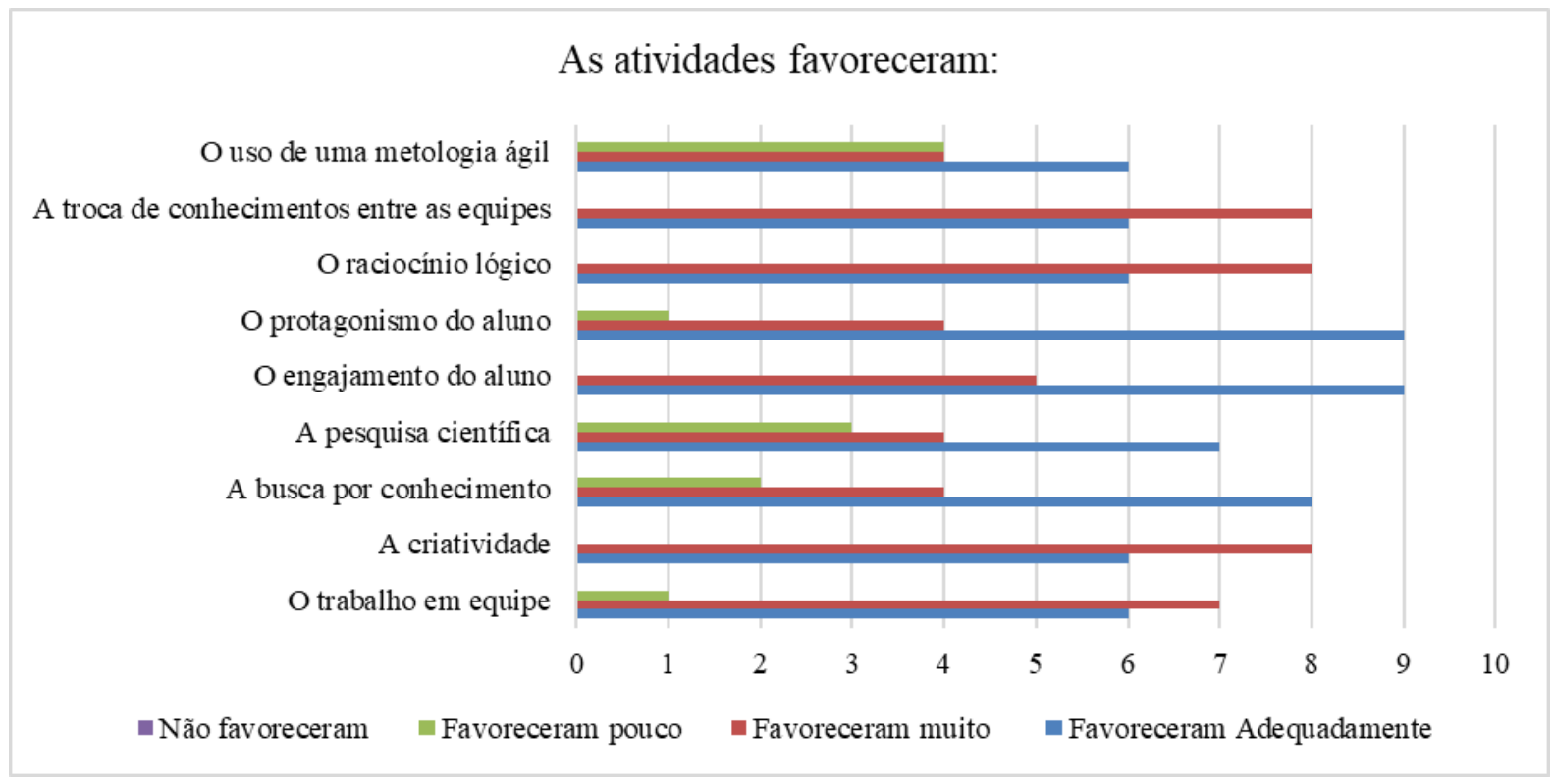

Fonte: Elaborado pelo(s) autor(es), 2019

Neste contexto, a utilização da robótica educacional permitiu o desenvolvimento de atividades que podem ser relacionadas com os componentes de hardware de forma adequada, entretanto, alguns itens foram mais compreendidos do que outros. Conforme ilustra o Gráfico 5, os conceitos de memória, $\mathrm{CPU}$ e dispositivos de E/S tiveram um nível de compreensão maior quando comparados com os outros conceitos trabalhados.

Gráfico 5 - Compreensão dos conceitos trabalhados com a RE

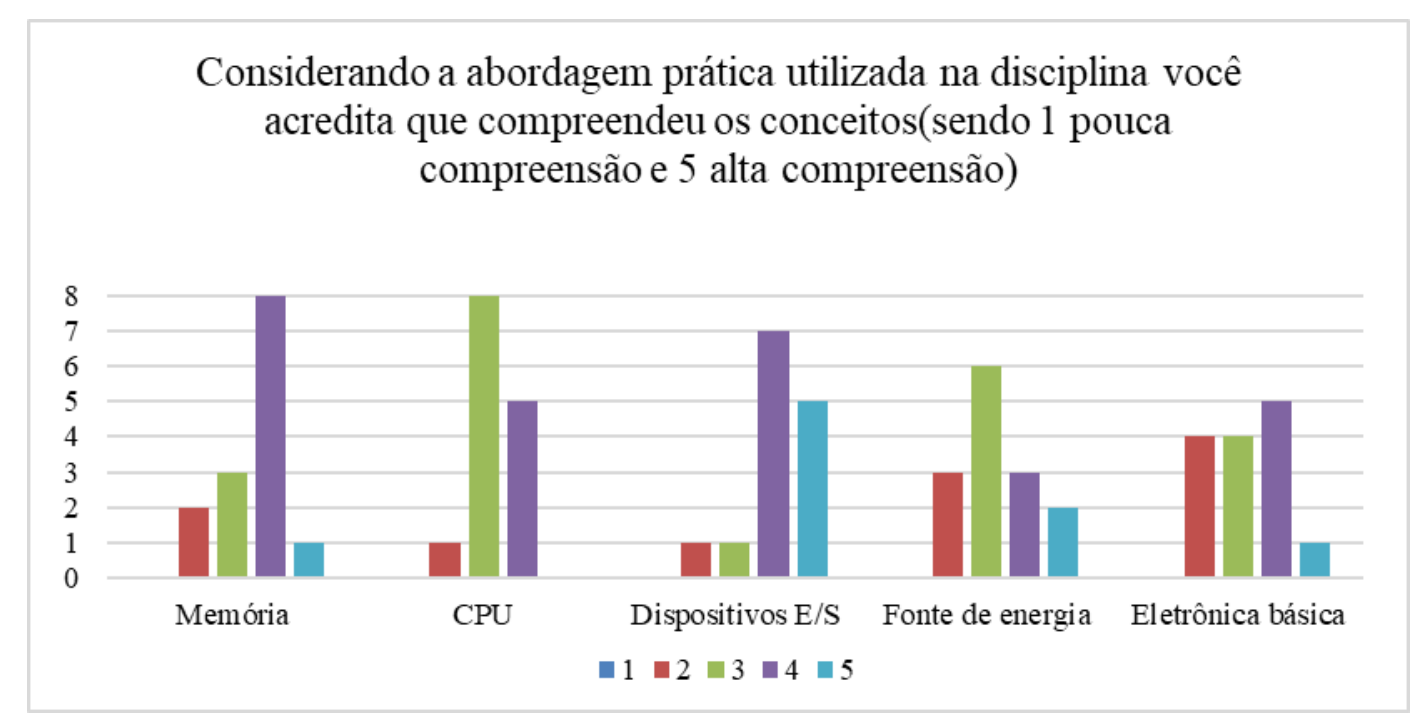

Fonte: Elaborado pelo(s) autor(es), 2019

Além do desenvolvimento satisfatório das atividades, a utilização da robótica como uma ferramenta para ensino dos conceitos de hardware foi bem aceita pelos estudantes, quando $86 \%$ mostrou-se favorável ao uso da RE novamente. As atividades que envolvem montagem de dispositivos robóticos instiga questionamentos no aluno e auxilia no relacionamento de diferentes conhecimentos e competências, além de estimular a investigação motivada pela 
curiosidade, "permitindo que o aluno extrapole os conhecimentos individuais de cada disciplina" (SANTOS; NASCIMENTO; BEZERRA, 2010, p. 2)

Quanto aos aspectos negativos, $43 \%$ dos alunos apontaram que o tempo destinado para o desenvolvimento do projeto foi insuficiente, visto que muitos nunca tinham tido contato com a RE. Assim, percebe-se que desenvolver a atividade de forma mais espaçada poderia favorecer o processo. Os alunos sugeriram também que os guias de referência fossem atualizados para conterem mais informações e exemplos de uso sobre os componentes utilizados.

\section{Considerações finais}

O uso de uma nova abordagem de ensino em hardware de computadores, através de dispositivos robóticos, mostrou-se capaz de estimular e aperfeiçoar o processo de aprendizagem tornando as atividades mais práticas e atrativas para os alunos. A adoção de metodologias ativas possibilita que os estudantes compreendam mais o conteúdo e que a aquisição do conhecimento tenha um efeito mais prolongado. Com o uso da ABP foi possível compensar a falta de infraestrutura e a utilização exagerada de soluções virtuais, favorecendo situações reais e contextualizadas.

$\mathrm{Na}$ análise docente, o aspecto mais evidente é a dificuldade em romper a passividade que alguns alunos possuem, pois, ao encontrarem um obstáculo, não buscam a solução para o problema. A tendência é que eles fiquem aguardando a resolução por parte professor, já que esta forma é mais comum ao seu cotidiano escolar, replicar a solução dada pelo professor. Esse fato gerou desmotivação desses indivíduos, porque, conforme a complexidade do projeto aumentava a cada aula, alguns grupos ficavam parados, aguardando a solução do professor. Outro ponto que se mostrou preocupante foi a falta de subsunçores relativos a aspectos básicos de energia e programação disponíveis na estrutura cognitiva dos alunos, os quais já deveriam estar presentes devido aos pré-requisitos impostos pelo currículo do curso.

A utilização da prática pedagógica, proposta neste trabalho, mostrou-se uma alternativa capaz de minimizar os problemas de infraestrutura, suprir a falta de recursos e consequentemente melhorar a qualidade das aulas ministradas com o desenvolvimento de atividades práticas, atrativas e distantes da exclusiva metodologia expositiva. Acredita-se que essa estratégia pedagógica possa melhorar o processo de ensino e aprendizagem em cursos de nível técnico. Além disso, ela conseguiu minimizar as lacunas no aprendizado das disciplinas de hardware estudadas no curso.

\section{Referências}

AUSUBEL, D. P. Aquisição e retenção de conhecimentos: uma perspectiva cognitiva. Lisboa: Platano, 2000.

BACICH, L.; MORAN, J. (org.). Metodologias Ativas para uma Educação Inovadora: uma Abordagem Teórico-Prática. Porto Alegre: Penso, 2018.

BARBOSA, E. F.; MOURA, D. G. De. Metodologias Ativas de Aprendizagem na Educação Profissional e Tecnológica. Boletim Técnico do Senac, [s. 1.], v. 39, n. 2, p. 48-67, 2013. Disponível em: http://www.bts.senac.br/index.php/bts/article/view/349/333. Acesso em: 30 set. 2018.

BENDER, N. W. Aprendizagem Baseada em Projetos: educação diferenciada para o século 
XXI. Porto Alegre: Penso, 2014.

BORGES, K. S.; FAGUNDES, L. D. C. A teoria de Jean Piaget como princípio para o desenvolvimento das inovações. Educação, [s. 1.], v. 39, n. 2, p. 242, 2016.

BRUM, L. M. da L.; PINHO, L. B. De; CAMARGO, S. da S. Metodologia de Aplicação da Realidade Aumentada no Ensino de Arquitetura de Computadores. International Journal of Computer Architecture Education (IJCAE), [s. 1.], v. 4, n. 1, p. 17, 2015. Disponível em: https://www.researchgate.net/publication/324574094_Metodologia_de_Aplicacao_da_Realid ade_Aumentada_no_Ensino_de_Arquitetura_de_Computadores. Acesso em: 16 nov. 2018.

BRUM, L. M. da L.; PINHO, L. B. De; CAMARGO, S. da S. Avaliação do Uso de Realidade Aumentada no Ensino de Arquitetura e Organização de Computadores. International Journal of Computer Architecture Education (IJCAE), [s. 1.], v. 6, n. 1, p. 10, 2017. Disponível em:

https://www.researchgate.net/publication/324574259_Avaliacao_do_Uso_de_Realidade_Au mentada_no_Ensino_de_Arquitetura_e_Organizacao_de_Computadores. Acesso em: 16 nov. 2018.

BUCK INSTITUTE FOR EDUCATION. Aprendizagem baseada em projetos: guia para professores do ensino fundamental e médio. Porto Alegre: Artmed, 2008.

CALAZANS, N. L. V.; MORAES, F. G. Integrating the teaching of computer organization and architecture with digital hardware design early in undergraduate courses. IEEE Transactions on Education, [s. 1.], v. 44, n. 2, p. 109-119, 2001. Disponível em: http://ieeexplore.ieee.org/document/925805/. Acesso em: 14 nov. 2018.

CAMPOS, F. R. Robótica Educacional no Brasil: Questões em aberto, desafios e perspectivas futuras. RIAEE: Revista Ibero-Americana de Estudos em Educação, Araraquara, [s. 1.], v. 12, n. 4, p. 2108-2121, 2017.

COSTA JUNIOR, A. de O. Uma estratégia utilizando robótica para o ensino dos conceitos de velocidade e aceleração escalares. 2017. INSTITUTO FEDERAL DE EDUCAÇÃO, CIÊNCIA E TECNOLOGIA DO AMAZONAS, [s. 1.], 2017.

DAMASCENO, E. F.; DAMASCENO, T. V. P. Experimentação pedagógica de laboratórios virtuais para ensino de manutenção de microcomputadores. Revista E-Tech: Tecnologias para Competitividade Industrial - ISSN - 1983-1838, [s. 1.], p. 125-140, 2013. Disponível em: http://etech.sc.senai.br/index.php/edicao01/article/view/318. Acesso em: 19 ago. 2018.

DAMASCENO, E. F.; OLIVEIRA, D. C. Um Ambiente Virtual para Ensino de Instalação e Manutenção de Microcomputadores. Global Science and Technology, [s. 1.], v. 6, n. 1, p. 171-183, 2013. Disponível em: http://www.bibliotekevirtual.org/index.php/2013-02-07-0302-35/2013-02-07-03-03-11/208-gst/v06n01/1083-v06n01a16.html. Acesso em: 19 ago. 2018 .

DOBGENSKI, J. Uma experiência no ensino de hardware. Workshop de Educação em Informática (WEI), [s. 1.], p. 11, 2008. Disponível em: http://www2.sbc.org.br/csbc2008/pdf/arq0117.pdf. Acesso em: 19 ago. 2018. 
FILIPPO, D.; ROQUE, G.; PEDROSA, S. Pesquisa-ação: possibilidades para a Informática Educativa. In: Metodologia de Pesquisa Científica em Informática na Educação: Abordagem Qualitativa de Pesquisa, v.3, [s.l: s.n.]. p. 29.

FORNAZA, R. Robótica educacional aplicada ao ensino de física. 2016. Universidade de Caxias do Sul, [s. 1.], 2016.

GOMES, M. Reciclagem Cibernética e inclusão digital: uma experiência em informática na educação. In: LAGO, C. (ed.). Reescrevendo a educação. Chapecó: Sinproeste, 2007.

GUARENTI, R. G. Robótica educacional na educação profissional e tecnológica: desafios e possibilidades, um estudo de caso, superando desafios de aprendizagem. 2015. Instituto Federal de Educação, Ciência e Tecnologia Sul-rio-grandense, [s. 1.], 2015.

GUERRA, E. L. de A. Manual da pesquisa qualitativa. Belo Horizonte: Grupo Anima Educação, 2014. Disponível em:

http://disciplinas.nucleoead.com.br/pdf/anima_tcc/gerais/manuais/manual_quali.pdf. Acesso em: 19 nov. 2018.

JOCELEN, T. et al. Metodologia de ensino: aprendizagem baseada em projetos (PBL). Cobenge: XL Congresso Brasileiro de Educação em Engenharia, [s. 1.], 2012. Disponível em: http://www.abenge.org.br/cobenge/arquivos/7/artigos/104325.pdf. Acesso em: 5 nov. 2018.

MARÇAL, E. et al. A Utilização de Dispositivos Móveis com Ambientes Tridimensionais como Ferramenta para Favorecer o Ensino de Hardware. Brazilian Symposium on

Computers in Education. Simpósio Brasileiro de Informática na Educação: SBIE, [s. 1.], v. 1, n. 1, 2009. Disponível em: http://br-ie.org/pub/index.php/sbie/article/view/1146/1049. Acesso em: 19 ago. 2018.

MARTINS, V. F. et al. PC-AR: Apoio ao Ensino de Organização de Computadores utilizando Realidade Aumentada. Brazilian Symposium on Computers in Education. Simpósio Brasileiro de Informática na Educação: SBIE, [s. 1.], v. 25, n. 1, p. 862, 2014. Disponível em: http://www.br-ie.org/pub/index.php/sbie/article/view/3021/2532. Acesso em: 14 nov. 2018.

MCROBERTS, M. Arduino Básico. 1. ed. São Paulo: Novatec, 2011.

MEC. Catálogo Nacional de Cursos Técnicos. Brasília/DF. Disponível em: http://portal.mec.gov.br/component/content/article?id=52031. Acesso em: 5 ago. 2018.

MENDEZ, C. S. R. et al. Uma Abordagem Integrada de Hardware e Software para o Ensino de Organização e Arquitetura de Computadores. Brazilian Symposium on Computers in Education. Simpósio Brasileiro de Informática na Educação - SBIE, [s. 1.], v. 29, n. 1, p. 1711, 2018. Disponível em: http://www.br-ie.org/pub/index.php/sbie/article/view/8133/5824. Acesso em: 14 nov. 2018.

MEURER, H. Ferramenta de gerenciamento e recomendação como recurso na aprendizagem baseada em projeto em design. Tese (Doutorado), Universidade Federal do Rio Grande do Sul, Programa de Pós-graduação em Informática na Educação (PPGIE), Porto Alegre, 2014. 
MONTEIRO, R. L.; PINTO, A.; DOS SANTOS, S. C. O Uso de PBL e da Abordagem Ágil Kanban em Residência de Software para o Setor de Telecomunicação, 2012.

MORAN, J. Metodologias ativas para uma aprendizagem mais profunda, 2013.

Disponível em: http://www2.eca.usp.br/moran/wp-

content/uploads/2013/12/metodologias_moran1.pdf. Acesso em: 1 nov. 2018.

MOREIRA, M. A. Teorias de aprendizagem. São Paulo: EPU, 1999.

MOREIRA, M. A. O que é afinal Aprendizagem Significativa. Qurriculum, [s. 1.], 2012.

Disponível em: <www.if.ufrgs.br./ moreira>. Acesso em: 16 jul. 2018.

NASCIMENTO, G. J. Do. Utilização de Conceitos Básicos de Matemática e Experimentos de Robótica para a Compreensão de Fenômenos Físicos. Dissertação (Mestrado Profissional em Matemática em Rede Nacional Utilização de Conceitos Básicos de Matemática e Experimentos de Robótica para a Compreensão de Fenômenos Físicos), Lavras, Minas Gerais, 96p. 2014.

OLIVEIRA, C. T. C. De. Novas tecnologias aplicadas à educação. São Paulo: Senac, 2018.

OLIVEIRA, S. Internet das Coisas com ESP8266, Arduino e Raspberry Pi. São Paulo: Novatec, 2017.

PEINADO, J.; GRAEML, A. R. Administração da produção: operações industriais e de serviços. Curitiba, PR: UnicenP, 2007.

PRASAD, P. W. C. et al. Using simulators for teaching computer organization and architecture. [s. 1.], 2015. Disponível em:

https://onlinelibrary.wiley.com/doi/pdf/10.1002/cae.21699. Acesso em: 13 ago. 2018.

RAABE, A. L. A; ZORZO, A F; FRANGO, I; RIBEIRO, L; GRANVILLE, L. Z;

SALGADO, L; CRUZ, M. J. K.; BIGOLIN, N.; CAVALHEIRO, S. A. C.; FORTES, S. Referenciais de Formação em Computação: Educação Básica. In: Congresso da Sociedade Brasileira de Computação, 2017, Anais... [s.1: s.n.] Disponível em:

https://www.sbc.org.br/documentos-da-sbc/summary/131-curriculos-de-referencia/1166referenciais-de-formacao-em-computacao-educacao-basica-julho-2017. Acesso em: 25 nov. 2019.

SANTOS, F. L.; NASCIMENTO, F. M. S.; BEZERRA, R. M. S. REDUC: A Robótica Educacional como Abordagem de Baixo Custo para o Ensino de Computação em Cursos Técnicos e Tecnológicos. Anais do Workshop de Informática na Escola, [s. 1.], v. 1, n. 1, p. 1304-1313, 2010. Disponível em: http://www.br-ie.org/pub/index.php/wie/article/view/2053. Acesso em: 9 out. 2018.

SANTOS, K. C. Protótipo de um Objeto Digital de Aprendizagem para Aplicação de Métodos de Ensino em Montagem e Manutenção Básica de Microcomputadores. 2013. Universidade Estadual do Ceará, [s. 1.], 2013. Disponível em:

https://sucupira.capes.gov.br/sucupira/public/consultas/coleta/trabalhoConclusao/viewTrabalh oConclusao.jsf?popup=true\&id_trabalho=681914. Acesso em: 19 ago. 2018.

SARKAR, N. I.; CRAIG, T. M. A Low-Cost PIC Unit for Teaching Computer Hardware 
Fundamentals to Undergraduates. The SIGCSE Bulletin, [s. 1.], v. 88, n. 2, 2007. Disponível em: http://delivery.acm.org/10.1145/1280000/1272892/p88-sarkar.pdf. Acesso em: 13 ago. 2018 .

TORCATO, P. O robô ajuda? Estudo do impacto do uso de robótica educativa como estratégia de aprendizagem na disciplina de aplicações informáticas. In: II CONGRESSO INTERNACIONAL TIC E EDUCAÇÃO 2012, Lisboa. Anais... Lisboa Disponível em: http://ticeduca.ie.ul.pt/atas/pdf/215.pdf. Acesso em: 30 set. 2018.

Recebido em dezembro de 2019.

Aprovado em maio de 2020. 